\title{
Research on China's Cross-Border E-Commerce Shared Logistics Overseas Warehouse Construction
}

\author{
Caiyun Lin \\ Yunnan College of Business Management \\ Kunming, China
}

\begin{abstract}
In recent years, China's cross-border ecommerce has entered a period of rapid development, and the overall transaction volume has maintained a growth rate of more than $20 \%$ for several consecutive years. However, at the same time as the rapid development of cross-border ecommerce in China, cross-border logistics has incurred problems such as high cost, long transportation and distribution time, and difficulties in returning and exchanges, which seriously restricts the development of cross-border ecommerce, traditional cross-border logistics. It is difficult to solve these problems. A new cross-border shared logistics model - overseas warehouses came into being. Although overseas warehouses can solve most problems of cross-border e-commerce enterprises and cross-border logistics, the development of China's overseas warehouses has also encountered many difficulties. This paper first introduces the development status of cross-border e-commerce industry and cross-border e-commerce logistics, especially shared logistics overseas warehouses, and then deeply analyzes the reasons for the development of overseas warehouses. Finally, comments and suggestions on these issues are made from both macro and micro aspects.
\end{abstract}

Keywords-cross-border e-commerce logistics; overseas warehouse; shared logistics

\section{INTRODUCTION}

In recent years, under the background of the continuous slowdown in the growth of China's import and export trade volume, cross-border e-commerce has developed rapidly in China. From China's cross-border e-commerce penetration rate, that is, cross-border e-commerce transactions account for import and export trade. According to the proportional analysis, the proportion of cross-border e-commerce transactions in China has been increasing year by year, from $4.0 \%$ in 2008 to $29.51 \%$ in 2018 , reaching 9 trillion yuan. Cross-border e-commerce gradually occupied the market share of the traditional foreign trade industry, and the volume of transactions and the types of trading products continued to expand. Judging from the scale of China's cross-border ecommerce import and export transactions, the current export cross-border e-commerce dominates, but the proportion of imported e-commerce is also increasing year by year. China's

*Fund: The Yunnan Provincial Department of Education Science Research Fund Project "Investigation on the Development of Cross-border E-Commerce Overseas Shared Logistics Based on the Perspective of Shared Economy", Project No.: 2018JS838. export industry has the advantage of low cost and government incentives, so China's cross-border e-commerce export transactions are larger than imports. According to the statistics of the Ministry of Commerce, the Bureau of Statistics and the General Administration of Customs, China's export cross-border e-commerce transactions accounted for $78.9 \%$ of the total transaction volume in 2018 but with the increase in domestic consumption, the proportion of China's imported cross-border e-commerce transactions in cross-border transactions Gradually, it rose from $4.2 \%$ in 2008 to $21.1 \%$ in 2018 , with cosmetics, maternal and child daily necessities occupying more and more market share. As an important part of cross-border ecommerce, cross-border logistics is closely related to crossborder e-commerce. However, with the rapid development of cross-border e-commerce in China, problems such as high cost, long transportation and distribution time, and difficult return and replacement of goods have seriously restricted the development of cross-border e-commerce, which has become the bottleneck of the development of cross-border ecommerce. With the continuous expansion of cross-border ecommerce, the existing logistics warehouses in seven pilot cities and ten bonded areas in China are still unable to meet the actual needs.

\section{CURRENT Status OF CHINAqS CROSS-BORDER E- COMMERCE OVERSEAS WAREHOUSE CONSTRUCTION}

\section{A. Different Logistics Modes of Cross-border E-commerce in China}

The main mode of cross-border logistics in China is mainly based on international postal parcels and international express delivery. Although there are also cross-border transportation modes of centralized transshipment, the proportion is relatively small. International express delivery is mainly represented by FedEx, UPS and DHL, which controls most of the international express delivery market. Although international express delivery is fast and safe, it can track logistics information in time, but the cost is relatively high, and it is engaged in cross-border electricity in China. For SMEs, the cost is too high, the cost is too large, and the profit margin of the enterprise is seriously compressed. Therefore, due to cost considerations, most of the sellers engaged in cross-border e-commerce in China are mainly based on international postal parcels. The cost is low and the cost is low, but the logistics cycle is long and the 
infrastructure and shared logistics information. Overseas delivery links, similar to domestic delivery and express delivery services, overseas warehouse service providers and local express delivery companies to establish cooperative relationships, and complete "last mile" distribution by local logistics companies with wide coverage, high efficiency and low cost. The local logistics company has a relatively complete layout of the local logistics network. Compared with the overseas import warehouse, the logistics cost of the distribution is lower. Sharing the logistics infrastructure of the local express logistics company is bound to optimize the "last mile". "The delivery service." After-sales service, one of the advantages of overseas warehouses is that it can help cross-border sellers to solve the after-sales service problems of products. Overseas warehouse service providers can share the local jumping market or second-hand trading websites by means of "shared return and exchange stocks". Share the return product information, help the seller to deal with these goods that need to be "secondary sales, reduce the return cost of the seller, and the company itself can also obtain additional income to achieve a win-win situation.

\section{Current Status of China's Overseas Warehouse Construction}

At present, China's overseas warehouses have three typical business models: self-built mode, cooperation with third parties and one-stop matching.

\section{1) Self-built mode}

Self-built mode refers to the establishment of a dedicated overseas warehouse for overseas cross-border e-commerce companies. The representative enterprise is Lanting. Whether cross-border e-commerce companies choose to build their own overseas warehouse models need to consider the following factors:

\section{- Location factors}

There are many factors affecting the location of overseas warehouses, such as distance from consumers and ports, transportation and transportation conditions, and natural conditions. Since cross-border e-commerce enterprises are far away from the target market and lack understanding of the target market countries, it is necessary to conduct research in advance, compare the advantages and disadvantages of different warehouse addresses, and select the appropriate warehouse address.

\section{- Cost control}

The self-built overseas warehouse model requires a large amount of construction cost in the early stage, and it also costs management costs during operation, and it is difficult to obtain investment returns in the short term. At present, the countries that establish cross-border e-commerce overseas warehouses in China are mainly in Europe and the United States. The cost of these places is much higher than that of domestic ones. Generally, cross-border e-commerce enterprises are difficult to bear the huge investment in the previous period.

\section{- Management problems of team members} quality preservation of the products. It is a new form of flexible integration of shared storage space, shared 
Overseas warehouses need to hire local staff overseas. Therefore, it is necessary to understand the legal policies and labor treatment issues of the host country before, and overcome cultural differences and communication obstacles. Overseas warehouses are still a new model combined with the latest technology of the Internet, requiring a large number of professional technical information talents to manage the supply chain and warehousing.

\section{2) Cooperation mode with third parties}

The mode of cooperation with third parties refers to the mode of cooperation between cross-border e-commerce companies and third-party enterprises to share overseas warehouses, including the leasing of third-party overseas warehouses and the establishment of overseas warehouses by both parties. Among them, Dalong.com represents the enterprise and actively the target market seeks cooperation with third parties. The cooperation model with third parties, on the one hand, the two sides will share the cost of opening a position to ease the financial pressure on cross-border ecommerce, on the other hand, they can also use the familiar knowledge of the target market in the third-party country to accelerate the process of cross-border e-commerce construction and cross-border E-commerce companies are more quickly integrated into the target market, adapt to the environment of the host country, and avoid unnecessary cultural conflicts and contradictions.

\section{3) One-stop supporting service mode}

The one-stop supporting service model refers to a series of services that the logistics company establishes overseas warehouses overseas and provides goods transportation from domestic to overseas. The typical representative enterprise is to deliver the four-way express delivery. The logistics service of the Quartet express delivery has spread throughout most of the world, and the Quartet Express has chosen to establish warehouses overseas to provide international logistics services with cross-border e-commerce companies as the core of overseas warehouses, greatly improving transportation efficiency. Warehousing is an important part of logistics. It is a logistics company that started with traditional logistics services. Warehouse is a professional field of its management and has accumulated certain warehouse management experience. The construction of overseas warehouses can make use of these warehouse management experience and understanding of the target market, provide professional logistics services for crossborder e-commerce enterprises, and rationally divide the work, improve the efficiency and benefits of cross-border ecommerce companies and logistics companies. The crossborder e-commerce sector is more specialized.

According to the analysis of the above three typical business models of overseas warehouses, the self-built model is the most flexible and can effectively control and manage commodity logistics. The other two models do not have such good advantages, but at the same time they have the highest cost and risk and are suitable for the market. Large crossborder e-commerce companies with large market share and strong financial strength, such cross-border e-commerce companies can choose to build their own overseas warehouses and enjoy exclusive resources. However, in fact, there are not many large-scale cross-border e-commerce companies with strong financial strength. China is more of a slow-growing small and medium-sized cross-border ecommerce enterprise. The capital turnover is not so slow and flexible, and the risks that can be borne are small. This type of cross-border e-commerce company's cooperation with third parties is a more appropriate choice. Therefore, it is suitable for small and medium-sized cross-border ecommerce enterprises with small market share and weak capabilities. Although such enterprises already have certain strength and considerable sales, it is still difficult to lease overseas warehouses of large-scale cross-border e-commerce companies. Therefore, it is necessary to cooperate with thirdparty enterprises to utilize third-party professional logistics services. Such cross-border e-commerce companies currently account for a large proportion, and there is an urgent need to use third-party overseas warehouses to conduct business, and the demand for overseas warehouses is relatively stable. From the seller's point of view, the one-stop supporting service model is more professional and comprehensive than the other two, and the risk and cost of cross-border ecommerce companies are the smallest, making cross-border e-commerce companies the most worry-free, suitable for small or cross-border e-commerce companies that lack experience in logistics management. These cross-border ecommerce companies are looking at the vast global market and actively expanding their overseas business. However, due to the lack of management experience and lack of brand awareness in the initial stage, it is difficult to open up the global market. Therefore, it is possible to smoothly carry out foreign business with the help of one-stop supporting service mode. Therefore, the future development of the one-stop supporting service model is also very broad. In summary, the three overseas warehouse business models each have their own unique advantages in cost, management, and service. Therefore, cross-border e-commerce companies of different types and different development periods cannot choose the operating mode of overseas warehouses. First, understand the characteristics of your own company and the characteristics of various overseas warehouse operation modes, choose the most appropriate model, save costs and control risks.

\section{ThE PROBlEMS EXISTING IN THE CONSTRUCTION OF CROSS-BORDER E-COMMERCE OVERSEAS WAREHOUSES IN CHINA}

\section{A. Lack of Localization Services}

Whether overseas warehouse enterprises can provide high-quality localized services is an important factor affecting the competitiveness of enterprises. The so-called localized service is to solve the problems of language, marketing, data integration and legal trade disputes in crossborder transactions in the way that local people are used to. In cross-border trade, more and more sellers are paying attention to how to capture local consumption requirements, how to do localized marketing, localized distribution, localization promotion, etc., to maximize the diversity of overseas consumers demand. However, due to the limitation of space, it can only be achieved by means of overseas 
warehouses. At present, China's overseas warehouses have yet to be improved in the localization service. After surveying more than 200 sellers, Yicang Technology found that localization is the new appeal of many sellers to overseas warehouses, of which local demand research accounts for about 79\%, except for Yicang Technology. After research, CROV found that $80 \%$ of sellers have local data research needs, $29 \%$ of sellers have local craft design requirements, $25 \%$ of sellers have local procurement needs, and $11 \%$ of sellers have local assembly needs. In essence, the existing overseas warehouses cannot satisfy the localization demands of the sellers, resulting in the lack of localized services. The lack of local services is influenced by the traditional concept of operation. On the other hand, the localization construction itself is rich and complex, and cannot be completed by a single enterprise.

\section{B. The Overseas Warehouse Has a Low Technical Level and Lacks Professional Talents}

The development and application of overseas warehouse information technology requires professional supply chain management talents and information technology talents. However, due to the short development time of China's overseas warehouses, there is a relatively lack of professional supply chain management talents and information technology talents. For example, the automated three-dimensional warehouse greatly realizes information management, and it requires the operation and improvement of professionals, whether it is cargo location management, inventory management, or database management. The inventory information is not allowed to make the capital turnover cycle of cross-border e-commerce enterprises lengthened, which reduces the operation effect of funds and even disrupts the sales plan of cross-border e-commerce enterprises. At the same time, the procedures and operations of warehousing of overseas warehouses are not as good as those of domestic warehouses. The classification and placement process of goods on the shelves is slow, delaying the timely sales and delivery time. At present, the application of big data can greatly improve the operating efficiency of overseas warehouses, and can promote the upgrade of overseas warehouses. At present, the lack of professional talents hinders the timely updating of China's cross-border ecommerce overseas warehouses, and the application of new technologies is an urgent need for cross-border e-commerce companies and logistics enterprises.

\section{The Customer Service Level Is Not Enough}

Although China's overseas warehouses have facilitated customs clearance procedures in the first-way transportation, there are still large loopholes in the customer's service level, and frequent errors occur. According to the statistics of iResearch, about 25\% of customers complained that the overseas warehouses had missing or wrong hair, which reduced customer satisfaction. The competition of overseas warehouses is also reflected in the competition of service quality. At present, there are many overseas warehouses in the service plain stage, but few of them reach the level of service. Generally, the existing overseas warehouses only stay in the scale effect and cannot break through the existing service model. Overseas warehouses are also service providers for cross-border e-commerce companies. They should provide good services to consumers with cross-border e-commerce companies, use geographical advantages to pay attention to the needs of local consumers, and timely feedback demand information to cross-border e-commerce companies. If cross-border e-commerce companies do not have such demand information, it will be difficult to produce the products that local consumers need in a timely manner, which will lead to the risk of slow-moving and capital turnover of cross-border e-commerce enterprises.

\section{The Pressure on Overseas Warehouses Is Relatively High}

Overseas warehouses are not suitable for all goods. The profit of most overseas warehouses comes from the highspeed circulation of goods. On the contrary, if some largescale goods with slow sales or goods in the off-season greatly increase the inventory pressure, it will cause a short position. These products occupy a large area of overseas warehouses for a long time, so that overseas warehouses can no longer store the hot items in the current season, and cannot make full use of the space of overseas warehouses to maximize the benefits. At this time, if the large-scale goods with slow sales speed or the goods in the off-season are shipped back to China, the transportation costs are also very high, sometimes exceeding the value of the goods themselves, which makes the cross-border e-commerce enterprises fall into a dilemma. Dilemma: Continue to store goods will consume overseas warehouse space, and the cost of shipping back is unaffordable. The pressure on overseas warehouse stocks is also a major problem that continues to be solved.

\section{E. The Construction of Cross-border Logistics Policy Environment Is Lagging Behind, and the Legal Supervision Mechanism of Overseas Warehouses Is Not Perfect}

At present, the government advocates cross-border ecommerce, logistics and Internet to develop together, promote each other and expand overseas markets. In 2013, the Ministry of Commerce issued the "Guiding Opinions on Accelerating the Development of E-Commerce", which indicated that it is necessary to strengthen management in logistics management, credit evaluation, network settlement and industry supervision, and promote the development of cross-border e-commerce. In addition, the General Administration of Customs issued the "Announcement on the Supervision of Cross-border Trade E-Commerce Goods", which further regulated the entry and exit of cross-border ecommerce goods and strengthened supervision. Whether it is a cross-border e-commerce enterprise or an individual, it must accept the supervision of cross-border e-commerce goods by relevant customs departments. In addition, China Customs has improved the entry and exit procedures for cross-border e-commerce products and further standardized the cross-border e-commerce market. Despite the government's policy support, cross-border e-commerce overseas warehouses have a short development time, and all 
aspects of development are not mature, and still face many legal obstacles. In Russia's overseas warehouses, many companies are evading the fees they need to pay, using legal loopholes and choosing a "gray customs clearance" approach, which is likely to be discovered by Russian inspection authorities and customs, facing fines and legal liabilities. . In some countries, China's cross-border e-commerce companies have encountered very strict and unfair treatment, such as Russia's high tax on goods that are tax-free for China; Brazil imposes a 60\% tariff on Chinese goods over US\$50, making China cross Environmental e-commerce companies have taken on more tax. In addition, the tax evasion problem caused by loopholes in laws and regulations has also affected the international image of China's cross-border e-commerce overseas warehouses.

\section{SugGestions ON PROMOTING THE CONSTRUCTION} OF CROSS-BORDER E-COMMERCE OVERSEAS WAREHOUSES IN CHINA

\section{A. Building an Overseas Warehouse Alliance}

Set up an overseas warehouse alliance, and integrate some overseas warehouse enterprises with strong strength and complementary functional advantages through contract or contract, and operate overseas markets in the form of "overseas warehouse alliance". On the one hand, it is more advantageous in terms of alliances with companies from other countries. On the other hand, alliance members can also support each other, which is conducive to improving the overall service level of overseas warehouses, and even can purify and standardize the development environment of overseas warehouse industry.

\section{B. Multi-party Cooperation to Share Unsalable Inventory}

The unsalable backlog of overseas warehouse products has brought challenges to the seller's return of funds and continued operations. How to deal with these slow-moving products is a problem that must be solved in the development of overseas warehouses. In addition to the inevitable reasons for the return and replacement of goods, the most important reason is that the single sales channel leads to the backlog of inventory. Overseas warehouse service providers can help sellers deal with these slow-moving inventory in the form of "shared inventory" in operation, that is, publicly share the information of unsalable backlog to other cross-border sellers, e-commerce platforms, retailers at all levels, wholesalers. Businesses are even international students, allowing them to help deal with these products in a variety of ways.

\section{Enterprises Jointly Promote Localization}

The localization of overseas warehouses is the basis and premise for the further development of overseas warehouses. In the localization construction of overseas warehouse, the influence of the old ideas should be broken first, and it should be made clear that the operation and management mode of establishing overseas warehouse is totally different from that of establishing branches in China. Secondly, the localization of overseas warehouses is a very complicated and large project. It includes localized language, payment, marketing, delivery, after-sales service and legal team building. All of them require a large amount of manpower and material resources. However, the strength of a single company is limited, and it is impossible to take into account all aspects, and if the company adopts a "single-play" approach, it will inevitably lead to waste and idleness. Therefore, in order to reduce costs and maximize investment returns, the best way is to form an alliance of overseas warehouse service providers, strengthen alliances, and work together in the alliance. Each company is responsible for its own good links. Interoperability, sharing and sharing, just like the global postal network. The scope of postal services has basically covered all countries in the world. However, the construction of the global postal service system is not completed by a single country, but through cooperation. Each country is only responsible for the planning and construction of its own logistics network, and it can share postal resources all over the world. In the face of the current situation of localized missing services, overseas warehouse service providers can also follow suit.

\section{Relevant Policies of the Government to Improve Cross- border E-commerce Overseas Warehouses}

The development time of China's overseas warehouses is relatively short, and the legal policies for the permit, operation and supervision of opening positions are needed to be perfect. China must start with the actual problems of overseas warehouse development, from international logistics, overseas warehouse construction regulations, etc. In respect, we will improve relevant laws and regulations and provide a good development environment for overseas warehouse construction. We should pay special attention to credit and information security issues in cross-border trade activities, draw on international legal provisions and experience, improve regulatory measures, expand regulatory channels, and directly address the pain points, so as to treat different operation modes of overseas warehouses. At the same time, the government needs to improve the exit and entry supervision policies, improve the efficiency of commodity clearance.

\section{CONCLUSION}

This paper discusses the different logistics modes of cross-border e-commerce in China, the operation process of shared logistics overseas warehouse and the status quo of China's overseas warehouse construction, and puts forward several problems in the development of China's overseas warehouses: the unsalable backlog of inventory is difficult to handle; the lack of localization services and lack of compound talents; the construction of cross-border logistics policy environment is lagging behind, and the legal supervision mechanism of overseas warehouses is not perfect. Then it analyzes the causes of these problems. Finally, from the macro and micro aspects of the two sides to put forward opinions and suggestions, the macro aspect, advocates the establishment of an overseas warehouse alliance, the effective integration of resources among members of the alliance, the establishment of an overseas warehouse 
information sharing platform, to achieve the optimal allocation of overseas warehouse resources . On the micro level, firstly, the problem of unsalable inventory of overseas warehouses is solved by means of sharing enterprise stocks. Secondly, multiple overseas warehouse enterprises jointly promote localization and share the results of localization in a cooperative manner. Finally, on the government side, it is recommended that the government improve the relevant policies for cross-border e-commerce overseas warehouses.

\section{REFERENCES}

[1] Juliet Schor. Debating the Sharing Economy [R]. Great TransitionInitiative, 2014(10): 1- 14.

[2] Abbas Asosheh, Hadi Shahidi-Nejad, Hourieh Khodkari. A Model of a Localized Cross-Border E-Commerce [J]. i Business. 2012 (02).

[3] Rachel Botsman, Roo Rogers. What's Mine Is Yours: The Rise of Collaborative Consumption [M]. New York: HarperCollins, 2010.

[4] Zeng Tian. The status quo, opportunities and challenges of crossborder logistics overseas warehouse development [J], foreign trade. 2017 (06).

[5] Ge Yan. Problems and countermeasures for cross-border logistics overseas warehouses [J]. Journal of Shandong University of Finance, 2016, 28(3):77-82.

[6] Ren Fang. Warehousing Resources Sharing Model and Value Analysis [J]. Logistics Technology and Application, 2017, 22(2): 9092.

[7] Wang Wei. Overseas warehouses will become the new normal of ecommerce [J]. Import and Export Manager, 2015 (05): 74-75. 